\title{
Estimation of Body Fat Percentage in Oral Squamous Cell Carcinoma
}

BACKGROUND: The purpose of this study was to calculate the body fat percentage and learn its relationship with body mass index in oral squamous cell carcinoma.

MATERIALS AND METHOD: the study comprised of 31 oral squamous cell carcinoma patients and 28 controls. Body mass index was calculated for each individual by recording the height (in meters) and weight (in Kilograms). Prediction equations given by Deurenberg, Gallagher and Jackson-Pollock were used to calculate body fat percentage.

RESULTS: Definite correlation between body fat percent and body mass index was found in oral squamous cell carcinoma and controls. Comparisons of body fat percentages between both groups were found to be statistically significant in Gallagher $(\mathrm{p}=0.04)$ and Jackson-Pollock $(\mathrm{p}=0.03)$ equations.

CONCLUSION: This study suggests that body fat percentage can be a useful indicator for assessing severity of lipolysis due to cachexia in cancer patients. The study can help in evaluating nutritional status during postoperative care of cancer patients.

KEYWORDS: Body fat percentage, Body mass index, Prediction equations, Oral squamous cell carcinoma

\section{INTRODUCTION}

Malnutrition is frequently concomitant in patient with chronic diseases and it may be associated with adverse outcome in these individuals. It has been surveyed that up to $20 \%$ of patients with cancer die of the effects of malnutrition rather than of the malignancy itself. The prevalence of malnutrition in cancer patients varies by tumor type and disease stage. ${ }^{1}$ Many cancer patients have a wasting syndrome termed cachexia, which is characterized by loss of skeletal muscle and adipose tissue. Although extensive literature is available on the mechanisms behind muscle wasting, much less is known about the factors encouraging loss of adipose tissue in cancer patients. However, it is believed that increased fat cell lipolysis, resulting in loss of lipids from adipose tissue, is independent of malnutrition. ${ }^{2}$

Fat loss is frequently observed in advanced malignant disease, but may also occur in patients with early stage cancer when tumor volume is still relatively small. Studies in experimental animals have shown a progressive depletion of carcass fat stores during tumor growth. ${ }^{3}$ Fouladiun et al examined changes in body composition, diet, and inflammatory markers in cachectic patients with cancer. They found that anorexia and loss of body fat are the powerful predictors of mortality. ${ }^{4}$

Numerous methods are available to assess body composition, which include bioelectrical impedance, infra-red interactance and anthropometry such as skinfold thickness measurements or weight-height indices. For the assessment of body fat percentage (BF \%), a weight-height index is the most simple method. From the several available weight-height indices, the body mass index (BMI) seems to be the most appropriate. ${ }^{5}$ Undoubtedly body mass index (BMI) has been shown to correlate closely with body fat, irrespective of age, sex and ethnicity. ${ }^{6}$

In 1991 Deurenberg et al derived the prediction equations for the assessment of $\mathrm{BF} \%$ from $\mathrm{BMI}$, sex and age that provides accurate estimates of body composition. They found that it is inexpensive and does not rely on well-trained observers. Similar prediction equations were also derived by Gallagher and Jackson-Pollock. ${ }^{7}$

Numerous prospective studies have been performed for the estimation of body fat and cancer risk by using BMI and relevant anthropometric data. These prospective studies include esophageal, breast, prostate and gynecologic cancers. However there is very scanty data available for estimation of body fat percent in head and neck cancer, especially oral cancer. From this viewpoint the present study was thought up to calculate the body fat percentage (BF $\%$ ) in oral squamous cell carcinoma patients by using various body fat percentage equations byDeurenberg, Gallagher and Jackson-Pollock ${ }^{8}$ and correlate it with 
body mass index (BMI).

\section{MATERIALS AND METHODS}

Thirty-one histopathologically confirmed oral squamous cell carcinoma patients and 28 healthy controls were selected from the data available of previous study. Ethicalclearance was obtained from the Institutional Ethical Committee, People's College of Dental Sciences and Research Centre, Bhopal.Patients with history of chemotherapy, radiotherapy, oncosurgery, obesity, systemic diseases, bronchial asthma and drug allergies were excluded. BMI of each individual was calculated from the height and body weight using formula Body Mass Index $=$ Weight $/$ Height $(\mathrm{m} 2)$. BF\% for both the groups was calculated by using various equations (Table 1 ).

Statistical analysis: Means with standard deviation for BMI, body fat percent (BF \%), age and sex were calculated. Student's $t$ test was used for comparing the $\mathrm{BF} \%$ between controls and oral squamous cells carcinoma patients. Analysis of variance (ANOVA) was used to compare $\mathrm{BF} \%$ calculated by using various equations given in table 1 . Mean BMI and mean BF\% was correlated by using Pearson's correlation in both the groups.

\begin{tabular}{|c|c|}
\hline Researcher & Adult body fat Percentage \\
\hline Deurenberg 1 & $(1.20 \times \mathrm{BMI})+(0.23 \times$ Age $)-\left(10.8 \times\right.$ gender $\left.^{*}\right)-5.4$ \\
\hline Deurenberg 2 & $(1.29 \times$ BMI $)+(0.20 \times$ Age $)-\left(11.4 \times\right.$ gender $\left.^{*}\right)-8.0$ \\
\hline Gallagher & $(1.46 \times$ BMI $)+(0.14 \times$ Age $)-(11.6 \times$ gender $*)-10$ \\
\hline Jackson-Pollock & $(1.61 \times$ BMI $)+(0.13 \times$ Age $)-\left(12.1 \times\right.$ gender $\left.{ }^{*}\right)-13.9$ \\
\hline
\end{tabular}

Table 1. Equations for Calculation of Body Fat Percentage ( ${ }^{*}$ for males: gender $=1$ and for female: gender $=0$ )

\section{RESULTS}

Control group (group II) comprised 28 healthy individuals with age ranging from 22 to 70 years (mean age $48.68 \pm 14.68$ years) while study group (group I) comprised 31 oral squamous cell carcinoma patients with age ranging from 30 to 70 years (mean age $52.58 \pm 11.86$ years). Comparison of age and sex distribution in both the groups was not significant (Table 2).

\begin{tabular}{|c|c|c|c|c|}
\hline \multicolumn{1}{|c|}{ Parameters } & $\begin{array}{c}\text { Study } \\
\text { group } \\
\mathbf{n = 3 1}\end{array}$ & $\begin{array}{c}\text { Control } \\
\text { group } \\
\mathbf{n = 2 8}\end{array}$ & $\mathbf{p}$ & Inference \\
\hline Male/Female & $16 / 15$ & $18 / 10$ & 0.472 & Not significant \\
\hline $\begin{array}{c}\text { Age Range } \\
\text { (years) }\end{array}$ & $30-76$ & $\mathbf{2 2 - 7 0}$ & & Not significant \\
\hline $\begin{array}{c}\text { Mean age } \\
\text { (years) }\end{array}$ & $52.58 \pm 11.86$ & $\begin{array}{c}48.68 \pm \\
14.68\end{array}$ & 0.26 & Highly significant \\
\hline BMI (kg/m2) & $19.80 \pm 2.59$ & $23.14 \pm 2.22$ & 0.0000 & \\
\hline \multicolumn{2}{|c|}{ Table 2. Characteristics of Study (Group I) and Control (Group II) groups } \\
\hline
\end{tabular}

Comparison of BF\% between Group I and Group II were found to be significant statistically in Gallagher $(\mathrm{p}=0.045)$ and Jackson Pollock $(\mathrm{p}=0.034)$ equations but was not significant in both the Deurenberg equations (Table 3).

Correlations of $\mathrm{BF} \%$ calculated by various equations with BMI in Group I was found to be statistically 
highly significant, especially in the Jackson Pollock formula ( $\mathrm{p}=0.0008$ ) (Table 4$)$. In Group II, similar findings were observed (Table 5). Comparison of mean body fat percentage by various equations was found to be statistically significant in both the groups (Table 6).

\begin{tabular}{|c|c|c|c|c|}
\hline & Deurenberg 1 & Deurenberg 2 & Gallagher & Jackson-Pollock \\
\hline Group I & $24.89 \pm 6.25$ & $22.17 \pm 6.49$ & $20.29 \pm 6.67$ & $18.63 \pm 7.10$ \\
\hline Group II & $26.62 \pm 5.76$ & $24.25 \pm 5.88$ & $23.14 \pm 5.87$ & $21.89 \pm 6.16$ \\
\hline P Value & 0.14016 & 0.106402 & 0.045591 & 0.0341215 \\
\hline Inference & NS & NS & S & S \\
\hline
\end{tabular}

Table 3. Comparison of body fat percent in group I and II (T test)

\begin{tabular}{|c|c|c|c|c|c|}
\hline Formula & $\begin{array}{c}\text { Deurenberg } \\
1\end{array}$ & $\begin{array}{c}\text { Deurenbrg } \\
2\end{array}$ & \multicolumn{2}{c|}{$\begin{array}{c}\text { Gallagher } \\
\text { Jackson - } \\
\text { Pollock }\end{array}$} \\
\hline Body fat\% & $24.89 \pm 6.25$ & $22.17 \pm 6.49$ & $\begin{array}{c}20.29 \pm \\
6.67\end{array}$ & $18.63 \pm 7.10$ \\
\hline BMI & \multicolumn{3}{|c|}{$19.81 \pm 2.55$} \\
\hline p-value & 0.004 & 0.003 & 0.001 & 0.0008 \\
\hline
\end{tabular}

Table 4. Correlation of body fat percent with BMI in OSCC

\begin{tabular}{|c|c|c|c|c|}
\hline Formula & $\begin{array}{c}\text { Deurenberg } \\
1\end{array}$ & $\begin{array}{c}\text { Deurenbrg } \\
2\end{array}$ & Gallagher & Jackson - Pollock \\
\hline Body fat $\%$ & $26.62 \pm 5.76$ & $24.25 \pm 5.88$ & $23.14 \pm 5.87$ & $21.89 \pm 6.16$ \\
\hline BMI & & \multicolumn{3}{|c|}{$23.13 \pm 2.18$} \\
\hline p-value & 0.036 & 0.033 & 0.018 & 0.013 \\
\hline
\end{tabular}

Table 5. Correlation of body fat percent with BMI in controls

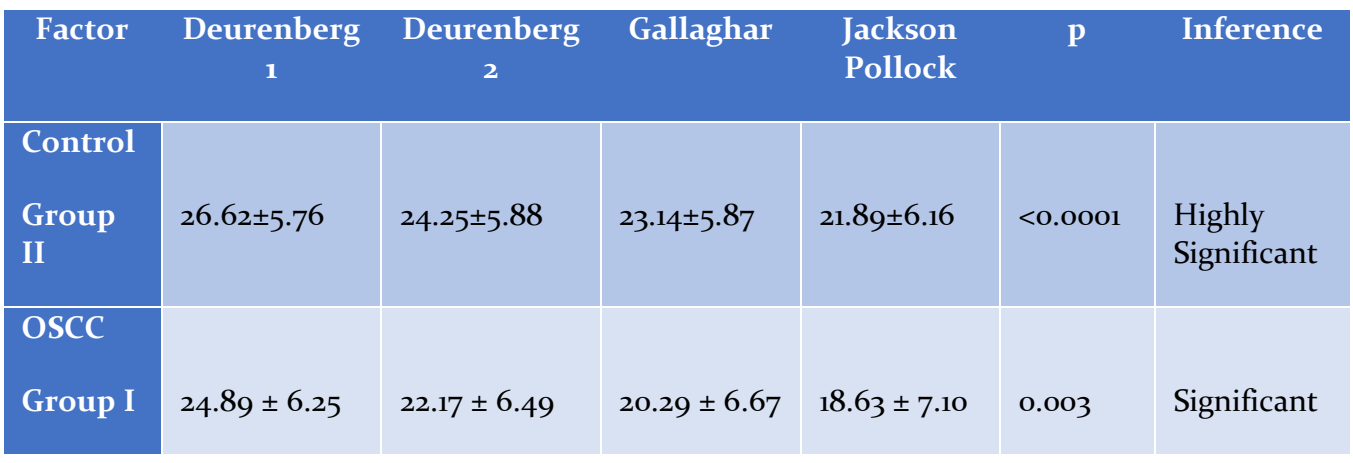

Table 6. Correlation of mean BF\% within the Group

\section{DISCUSSION}

For the assessment of BF\% in epidemiological studies, a weight-height index, especially body mass index (BMI) is the simplest method as minimum of equipment is needed. Body-weight and body height are relatively easy to measure as well-trained observer is necessary for the measurement of skinfold thickness and bioelectrical impedance for measurement of body fat. BMI seems to be the most appropriate parameter as its correlation with $\mathrm{BF} \%$ is high, and that with body height is low. Due to differences in body composition between males and females, and the age-related increase in body fat mass and the decrease in fat-free mass the relationship between $\mathrm{BF} \%$ and $\mathrm{BMI}$ is sex- and age-dependent. 
Thus assessment of BF\% from BMI, sex and age provides accurate estimates of body composition with the use of different prediction equations. ${ }^{5}$

We aimed at using these equations for the assessment of $\mathrm{BF} \%$ in available data of oral squamous cell carcinoma patients and the controls. There are other prediction equations for estimation of $\mathrm{BF} \%$ using BMI, age and gender (table 1). ${ }^{7}$ As there is no specific prediction formula for Indian population, all the four equations were referred for calculation of $\mathrm{BF} \%$.

In the present study, body fat percent in OSCC group was found to be significant when compared with the controls. Similar findings were also observed by Warnald et al. in female cancer patients although the difference was not significant in male patients with that of controls. ${ }^{8,9}$ We found statistically significant correlation between $\mathrm{BF} \%$ and $\mathrm{BMI}$ in oral squamous cell carcinoma patients. In controls also the $\mathrm{BF} \%$ was significantly correlated with BMI.

When the body fat percentages calculated by all equations were compared within the group, a statistically significant relation was found among those values. This finding was true for both the groups which suggest that body fat percent derived from either of these equations can be useful for assessment of body composition.

Laky et al. in gynecologic cancer patients found that fat mass was not significantly lowered in malnourished women than well-nourished women. A possible reason for the non-identification of malnourished patients via body density measurements may be that many of the women were obese before disease development. However, the feasibility of body density measurements in the clinical setting is limited, because of the limited availability of the machine in hospitals and because of the limited compliance of very ill patientsı.Wallstrom et al derived that general adiposity is not associated with prostate cancer. They found that $\mathrm{BF} \%$ estimated by other methods were slightly different from those for BMI. ${ }^{10}$

There seems to be a dual relationship between body fat and cancer, as in certain studies it shows negative correlation while some studies are having positive association. Murphy et al found the strong relation between obesity and colon cancer." Similar observations were also made by Kim et al for colonic adenoma and abdominal obesity. ${ }^{12}$ Steffen et al. found that higher BMI was related to higher risk of esophageal adenocarcinoma and also that higher waist circumference and waist heap ratio (as indicators of abdominal obesity) were associated with a higher risk of this cancer type. In contrast, they observed an inverse association for BMI and waist and hip circumference with risk of esophageal squamous cell carcinoma. ${ }^{13}$ This was also in accordance with Garavello et al., who observed that men with less abdominal fat had an increased risk of laryngeal cancer. ${ }^{14}$ The fat values in the patients with solid tumors were considerably lower than either those of normal age matched controls or patients with hematological cancers. ${ }^{15}$

There are some studies on comparison between body fat and body mass index in prediction of inflammatory and atherogenic lipid risk profiles in elderly women, in adolescents for anthropometric variables in Brazilian populationand evaluating diagnostic performance in Korean population. These studies have used parameters like DEXA and skinfold thickness. ${ }^{16,17,18}$ But there are very few studies using these prediction formulae especially in cancer patients.

Strengths of our study are availability of fewer studies of this kind in the past, particularly in head and neck region, referral of four prediction equations for estimation of $\mathrm{BF} \%$, common formula for both the genders. Nevertheless most of the studies done in past are based on electrical impedance and skin fold thickness. The major limitations in the study include a relatively small number of cases, randomly selected controls and unavailability of specific prediction formula for Indian population leading to inexact estimates.

\section{CONCLUSION}

Cachexia associated cancer is mostly governed by loss of body fat and is a major cause for morbidity in cancer patients. The estimation of body fat percent between preoperative and post operative cancer patients could be a useful tool for evaluation of their nutritional status. Use of any prediction formula can prove to be a simpler method in this regard.

Funding: The work was self-supported.

Ethical Approval: All procedure performed this study were in accordance with the Institutional Ethical Committee. The Ethical Clearance Certificate 
was obtained after the approval from Research Advisory committee if the Institute.

Informed consent: As no invasive procedure was performed the study, formal consent was not mandatory.

\section{REFERENCES}

1. Laky B, Janda M, Cleghorn G, Obermair A. Comparison of different nutritional assessments and body composition measurements in detecting malnutrition among gynecologic cancer patients. Am J ClinNutr2oo8; 87:1678-85.

2. Agustsson T, Ryden M, Hoffstedt J, van Harmelen V, Dicker A, Laurencikiene J, et al. Mechanism of Increased Lipolysis in Cancer Cachexia. Cancer Res 2007; 67(11):5531-7.

3. Younes RN, Noguchi Y. Pathophysiology of cancer cachexia. Rev. Hosp. Clín. Fac. Med. S. Paulo 2003;55(5):181-93.

4. Fouladiun M, Korner U, Bosaeus I, Daneryd P, Hyltander A, Lundholm KG. Body composition and time course changes in regional distribution of fat and lean tissue in unselected cancer patients on palliative care - correlations with food intake, metabolism, exercise capacity, and hormones. Cancer 2005; 103:2189-98.

5. Deurenberg P, Westrate JA, Seidell JC. Body mass index as a measure of body fatness: age- and sexspecific prediction formulas. Br J Nutr 1991; 65:10514.

6. Muralidhara DV. Body Mass Index and its Adequacy in Capturing Body Fat. Thai Journal of Physiological Sciences 2007;20(2):97-100.

7. Jackson AS, Stanforth PR, Gagnon J, et al. The effect of sex, age and race on estimating percentage body fat from body mass index: the Heritage Family Study. Int J Obes Relat Metab Disord. 2002;26(6):789-96.

8. Deurenberg P, Yap M, van Staveren WA. Body mass index and percent body fat. A meta-analysis among different ethnic groups. Int J Obes Relat Metab Disord 1998;22:1164-71.

9. Warnold I, LundholmK, Scherstén T. Energy balance and body composition in cancer patients. Cancer Res 1978;38:1801-7.

10. Wallstrom P, Bjartell A, Gullberg B, Wirfalt E. A prospective Swedish study on body size, body composition, diabetes, and prostate cancer risk. British Journal of Cancer 2009;100:1799-805.
11.Murphy TK, Calle EE, Rodriguez C, Kahn HS, Thun MJ. Body Mass Index and Colon Cancer Mortality in a Large Prospective Study. Am J Epidemiol 2000; 152: $847-54$.

12. Kim Y, Kim Y, Lee S. An association between colonic adenoma and abdominal obesity: a crosssectional study. BMC Gastroenterology 2009,9:4.

13. Steffen A, Schulze MB, Pischon T, Dietrich T, Molina E, Chirlaque MD, et al. Anthropometry and Esophageal Cancer Risk in the European Prospective Investigation into Cancer andNutrition. Cancer Epidemiol Biomarkers Prev 2009; 18: 2079-89.

14. Garavello W, Randi G, Bosetti C, Dal Maso L, Negri S, Barzan L, et al. Body size and laryngeal cancer risk. Annals of Oncology 2006; 17: 1459-63.

15. Cohn SH, Ellis KJ, Vartsky D, Sawitsky A, Gartenhaus W, Yasumura S, et al. Comparison of methods of estimating body fat in normal subjects and cancer patients. Am J ClinNutr. 1981; 34: 283947 .

16. Funghetto SS, Silva Ade O, de Sousa NM, Stival MM, Tibana RA, Pereira LC, et al. Comparison of percentage body fat and body mass index for the prediction of inflammatory and atherogenic lipid risk profiles in elderly women. Clin Interv Aging $2015 ; 10: 247-253$.

17. Frignani RR, Passos MA, Ferrari GL, Niskier SR, Fisberg M, de PáduaCintra I. Reference curves of the body fatindex in adolescents and their association with anthropometric variables. J Pediatr (Rio J) 2015;91:248-55.

18. Yoon JL, Cho JJ, Park KM, Noh HM, Park YS. Diagnostic performance of body mass index using the western Pacific regional office of World Health Organization reference standards for body fat percentage. J Korean Med Sci 2015;30:162-6. 
Cite this article as:

Gharote H, Pushpanshu K, Kaushik R, Gharote R. Estimation of body fat percentage in oral

Source of support: Nil, Conflict of interest: None declared

squamous cell carcinoma. Int Healthc Res J. 2019(11):291-296. doi: 10.26440/ihrj.v2i11.207

\section{AUTHOR AFFILIATIONS:}

1. MDS, Professor, Oral Medicine Division, Department of Basic and Preventive Sciences, Dentistry Program, Batterjee Medical College for Science and Technology, Jeddah, Kingdom of Saudi Arabia 21442

2. MDS, Associate Professor \& Head, Department of Dentistry, SriKrishna Medical College \& Hospital, Muzaffarpur, India

3. MDS, Associate Professor \& Head, Department of Dentistry, Bettiah Medical College \& Hospital, Bettiah, India

4. BDS, General Dental Practitioner

\section{*Corresponding Author:}

Dr. Kumar Pushpanshu

Associate Professor \& Head

Department of Dentistry

SriKrishna Medical College \& Hospital Muzaffarpur 842001, India
For article enquiry/author contact details, e-mail at: editor.ihri@gmail.com, editor@ihrjournal.com 